\title{
Prevention of congenital malformations for pregnant women: A predictive model based on a study in eastern Algeria's population
}

\author{
Adel Kalla, Lotfi Loucif, Mouloud Yahia \\ Laboratory of Biotechnology of Bioactive Molecules and Cellular Physiopathology, Department of Microbiology and \\ Biochemistry, Faculty of Science and Nature's Life, University of Batna 2, Batna, Algeria
}

\author{
Correspondence: Adel Kalla, Department of Microbiology and \\ Biochemistry, Faculty of Science and Nature's Life, University of \\ Batna 2, Fesdis, Batna 05000, Algeria. \\ Tel: +213661542948 . \\ E-mail: adel.kalla@gmail.com
}

Key words: Pregnancy risk prediction; pregnancy pathologies; nutrients; malformations.

Acknowledgments: This paper and the research behind it would not have been possible without the exceptional support of my supervisor Pr. Mouloud Yahia (RIP). I would like to express my sincere appreciation to my colleagues at Batna University for their technical assistance, provided insight and expertise that greatly assisted the research. I wish to extend my special thanks and greet everyone, who has supported the creation of this work. Great thanks to The DGRSDT (General Directorate of Scientific Research and Technological Development in Algeria), Departments of Health in hospitals of Mother and Child, especially The Head of the Department of Health in Batna, and Dr. Benakcha.

Contributions: AK led the study by being involved in data collection, performing the statistical analysis, interpreting the results, conceiving, and designing this article, and providing intellectual content revisions and suggestions for clarity and precision on the subject matter. MY has initiated the study as a physiopathologist and the head of the laboratory. LL has been part of the study as the new head of the laboratory. All authors read and approved the final review manuscript.

Competing interests: The authors have no conflicts of interest to declare.

Availability of data and material: Not available.

Ethical approval: The approval of a research ethics committee is not necessary in Algeria for an observational study since no intervention on patients took place in this study. Nonetheless, the study received clearance from the Internal Review Board of the University of Batna 2, Batna, Algeria.

Consent to participate and consent: Patients were not involved in the design, or conduct, or reporting, or dissemination plans of our research. Informed written consent was obtained from all individual participants included in the study before conducting the interviews.

Received for publication: 10 October 2020.

Accepted for publication: 4 July 2021.

${ }^{\circ}$ Copyright: the Author(s), 2021

Licensee PAGEPress, Italy

Journal of Biological Research 2021; $94: 9394$

doi:10.4081/jbr.2021.9394

This article is distributed under the terms of the Creative Commons Attribution Noncommercial License (by-nc 4.0) which permits any noncommercial use, distribution, and reproduction in any medium, provided the original author(s) and source are credited.

\begin{abstract}
The World Health Organization (WHO) defines congenital malformation as any gross abnormality present at birth even if it is not immediately recognized. Here, we aimed to identify the factors predisposing to congenital malformations in pregnant women in Eastern Algeria and the effect of the combination of several factors. 786 pregnant women were interviewed. Throughout our study, we sought to find answers, discuss the association between malformation exposure, identify the risk factors, and predict the occurrence of malformations using statistical analysis techniques. We developed a predictive model and we found that malformations were significantly higher for pregnant women aged over 34 (10.93; 95\% CI: 2.10 201.71, $\mathrm{p}=0.023)$, with a BMI over 25 (2.38; 0.91-7.04, $\mathrm{p}=0.091)$, hypertension $(2.18 ; 1.04-4.57, \mathrm{p}=0.038)$, anemia $(2.08 ; 0.98-4.35$, $\mathrm{p}=0.053)$ and infections $(2.32 ; 1.18-4.58 ; \mathrm{p}=0.015)$. Protecting factors against malformations includes diet moderate in meat (1.97; $0.73-4.98, \mathrm{p}=0.163)$ and rich in eggs, soft drinks, and fruit-vegetables $(2.69 ; 0.76-8.63, \mathrm{p}=0.106),(1.84 ; 0.74-4.43, \mathrm{p}=0.177),(3.08$; $0.56-13.28, \mathrm{p}=0.154)$; respectively. Knowing risk factors helps to establish predictive models and strategies to prevent malformations and highlights the link between malformations and multiple risk factors for the sake of protecting babies' lives.
\end{abstract}

\section{Introduction}

Pregnancy is a special period in a woman's life that requires regular and careful monitoring and treatment. During the nine months, the pregnant woman's body goes through several transformations, including physical, physiological, metabolic, and hormonal changes. This variety of changes ranges from common, permanent, and expected changes, to fewer familiar ones. Congenital malformations may occur during this period ${ }^{1,2}$ due to developmental anomalies occurring mainly during the period of organogenesis or fertilization or the first cell divisions. ${ }^{3}$ The congenital malformation is an irreversible abnormal conformation of a tissue, an organ, or a larger part of the body resulting from an intrinsic developmental disorder. ${ }^{4}$ According to the WHO, the incidence of malformations is estimated at $2-3 \%$ of live births for those diagnosed at birth or in the neonatal period, it is around 5 to $10 \%$ for less obvious anomalies and developmental disorders. ${ }^{5}$

In Algeria, like in most developing countries, there is a lack of reliable data on the occurrence and severity of pregnancy complications and their associated factors. The countryside and the rural parts of the country constitute grey areas, where pregnancy problems are still considered taboo, therefore few studies are carried out and few results are available. Thus, the objectives of this study 
are i) estimate the frequency of congenital malformations based on a prospective study in population groups from Eastern Algeria; ii) investigate and document potential associated risk factors in the studied population; iii) develop a predictive model of associated risk factors that can lead to a congenital malformation. Several statistical analyses including Multiple Correspondence and Hierarchical Clustering Analysis are applied using R language (v3.6.3) under the software RStudio (Version 1.3.959).

\section{Materials and Methods}

\section{Study design}

A prospective study of pregnancy period surveys was conducted on a cohort of pregnant women from the region of Batna, Eastern Algeria, over five years [2011-2015].

Pregnant women were randomly chosen from different localities, urban and rural. Data were collected and recorded through standardized questionnaires used during periodic medical consultations. The study was carried out at the Obstetrics and Gynecology Department of different Hospital's Mother-Child Units.

Included in the questionnaire, written informed consent was obtained from all participants.

\section{Population and Data collection}

The recruitment was carried out on pregnant women after they agreed to participate in the study. And this, only during the working days (weekdays excluding weekends).

The exclusion criteria were the refusal to be included in the study (no consent) and the absence of relevant data for this study.

The standardized questionnaire was introduced to the pregnant just before her first-trimester consultation, carried out by us in person in the presence of the health team.

The congenital malformations listed in our work were diagnosed during the ultrasound imaging of the second-semester consultation i.e. between the $22^{\text {nd }}$ and $27^{\text {th }}$ week of amenorrhea.
This study was conducted in a double-blinded way.

\section{Methods}

The methodology has consisted of statistical analysis techniques using $\mathrm{R}$ language (v3.6.3) under the software RStudio (Version 1.3.959). We performed univariate logistic regressions and built a generalized linear model to assess the association between each predictive factor and the risk, by selecting predictive factors that have a $\mathrm{p}$-value $<0.2 .{ }^{6}$ We then performed a Stepwise strategy which led to a final model containing only predictive factors. The model resulting from Stepwise is not necessarily the most efficient, and some factors will probably not have a significant effect on the risk. Therefore, the need of using other techniques to identify the influential factors such as Multiple Correspondence and Hierarchical Clustering Analysis is crucial.

\section{Results}

A total of 904 pregnant women have been recruited and surveyed. After screening, 118 were excluded due to the absence of relevant data for this study (Figure 1A). A sample of 786 pregnant women was retained and completed the study: 38/786 were identified as malformations' cases (4.83\%) and 748/786 women were not $(95.17 \%$, Figure 1B).

Several parameters were studied as risk factors potentially associated with congenital malformations, including Age, BMI, pathologies, and diets (Table 1).

According to the risk factor Age, we observed a high frequency of malformations in women aged over 34 to 50 , with $11.18 \%$ of women in the same age range and $2.42 \%$ of all study population.

While malformations frequency was higher in women with a BMI from 30 to 35 , with $7.65 \%$ of women in the same BMI range and $1.65 \%$ of the whole population. Malformation frequency was also notable for the other two adjacent ranges of BMI (] $25,30]$ and ]35,45]) and in pregnant women with pathologies.
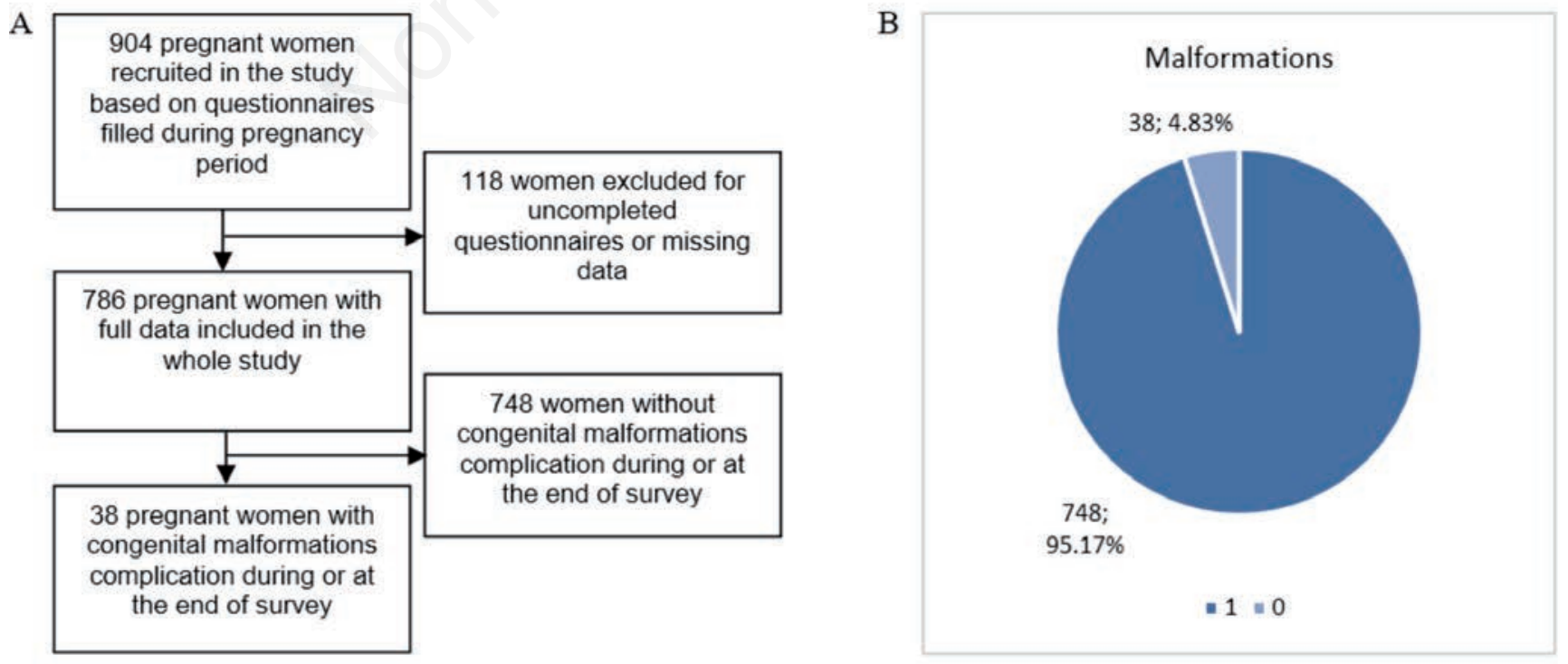

Figure 1. A) Flow chart showing the study population included malformations pregnancy complication; B) Prevalence of malformations in the included population of pregnant women (1: presence and 0 : absence of malformations). 
Concerning pathologies, we recorded a high frequency with pathologies, including diabetes $(9.52 \%)$, hypertension $(9.42 \%)$, kidney failure $(10.87 \%)$, anemia $(7.91 \%)$, or infections $(8.75 \%)$. However, malformations seem almost decreased in presence of stress with $5.63 \%$.

Regarding nutrients, a high incidence of malformations among women who consume moderate rates of fish and meat; and a high rate of fruit-vegetables and soft drinks; whereas malformations incidence was similarly distributed among other nutrients at different levels (Table 1).

To confirm primary suggestions recorded in Table 1, we used a univariate analysis (CI 95\%). However, in this Odds Ratio analysis, the association between risk factors and congenital malformation may be biased as we could not predict the influence of the combination of these factors. Therefore, we carried out multivariate analysis to better investigate influential factors. The results of the calculated $\mathrm{R}$ output are reported in Table 2.

Based on Table 2 results, we observe a strong association between malformations and age over 34 to 50 .

Similarly, a strong association is remarkably noted between malformations and BMI from 30 to 35. Same observation for BMI from 25 to 30 , while the high effect is noted for BMI from 35 to 45 .

Table 1. Malformations' distribution according to different risk factors.

\begin{tabular}{|c|c|c|c|c|}
\hline Risk factors & Level & & aation fr & ency \\
\hline & & No $\%$ * & Yes \%* & Frequency in range $\% \$$ \\
\hline Age & {$[17,24]$} & 18.32 & 0.13 & 0.69 \\
\hline & $(24,34]$ & 57.51 & 2.29 & 3.83 \\
\hline & $(34,50]$ & 19.21 & 2.42 & 11.18 \\
\hline BMI & {$[15,25]$} & 39.95 & 0.76 & 1.88 \\
\hline & $(25,30]$ & 32.32 & 2.16 & 6.27 \\
\hline & $(30,35]$ & 19.97 & 1.65 & 7.65 \\
\hline & $(35,45]$ & 2.93 & 0.25 & 8.00 \\
\hline Diabetes & 0 & 90.33 & 4.33 & 4.57 \\
\hline & 1 & 4.83 & 0.51 & 9.52 \\
\hline Hypertension & 0 & 73.16 & 2.54 & 3.36 \\
\hline & 1 & 22.01 & 2.29 & 9.42 \\
\hline Kidney Failure & 0 & 89.95 & 4.20 & 4.46 \\
\hline & 1 & 5.22 & 0.64 & 10.87 \\
\hline Anemia & 0 & 69.97 & 2.67 & 3.68 \\
\hline & 1 & 25.19 & 2.16 & 7.91 \\
\hline Infections & 0 & 64.63 & 1.91 & 2.87 \\
\hline & 1 & 30.53 & 2.93 & 8.75 \\
\hline Stress & 0 & 29.01 & 0.89 & 2.98 \\
\hline & 1 & 66.16 & 3.94 & 5.63 \\
\hline Meat & 1 & 65.14 & 2.93 & 4.30 \\
\hline & 2 & 16.28 & 1.40 & 7.91 \\
\hline & 3 & 13.74 & 0.51 & 3.57 \\
\hline Fish & 1 & 63.74 & 3.44 & 5.11 \\
\hline & 2 & 7.00 & 0.51 & 6.78 \\
\hline & 3 & 24.43 & 0.89 & 3.52 \\
\hline Eggs & 1 & 61.20 & 2.93 & 4.56 \\
\hline & 2 & 18.19 & 1.02 & 5.30 \\
\hline & 3 & 15.78 & 0.89 & 5.34 \\
\hline Dairy products & 1 & 25.19 & 1.40 & 5.26 \\
\hline & 2 & 58.91 & 3.05 & 4.93 \\
\hline & 3 & 11.07 & 0.38 & 3.33 \\
\hline Fruit-Vegetables & 1 & 35.75 & 2.04 & 5.39 \\
\hline & 2 & 56.11 & 2.42 & 4.13 \\
\hline & 3 & 3.31 & 0.38 & 10.34 \\
\hline Cereals & 1 & 54.96 & 2.80 & 4.85 \\
\hline & 2 & 19.59 & 0.89 & 4.35 \\
\hline & 3 & 20.61 & 1.15 & 5.26 \\
\hline Sweets & 1 & 49.87 & 2.67 & 5.08 \\
\hline & 2 & 30.53 & 1.27 & 4.00 \\
\hline & 3 & 14.76 & 0.89 & 5.69 \\
\hline Soft Drinks & 1 & 44.15 & 2.04 & 4.41 \\
\hline & 2 & 35.50 & 1.40 & 3.79 \\
\hline & 3 & 15.52 & 1.40 & 8.27 \\
\hline
\end{tabular}

Notes. For Age and BMI range: "[": indicates that the first value is included in the range, "(": indicates that the first value is not included in the range. For pathologies: (0) indicates absence and (1) presence of pathology. For nutrients: (1), (2), and (3) indicate levels of consumption, from low (1), moderate (2) to high (3). (*) Percent of all pregnant population. $\left({ }^{\$}\right)$ Percent of malformations in the same range or category. 
Concerning pathologies, the association between malformations with hypertension, anemia, and infections have been confirmed.

Whereas ORs calculation showed a potential positive association (significant at $\alpha=0.1$ ) between moderate rates of meat and high rates of soft drinks.

To adjust for a potential statistical co-founding bias, a multivariate analysis was performed and possible interactions between risk factors were tested using a generalized linear model. Therefore, the adjusted Odds Ratio and p-values (Table 2) confirmed some of the results reported in the univariate analysis. Age $>34$, high BMI $(130,35])$, hypertension, and infections are highly associated with malformations. The malformation is increased in women with $\mathrm{BMI}>25$.

Anemia has also been confirmed as an associated factor with malformations. Moderate consumption of meat preserved its effect; like a diet rich in eggs, fruit and vegetables, and soft drinks.

We observe that the effect of stress and diabetes has disappeared, which means that these factors are not significant in their influence on malformations.

The number of factors and their complexity as well as the results mentioned above, make it hard to validate an association between factors and their influence during the pregnancy period. The result of the Stepwise Strategy of congenital malformations model shows the selected model of influential factors which are age over 34 to 50, BMI from 25 to 35 , hypertension, anemia, and infections $(\mathrm{p}=0.004)$ with an $\mathrm{AIC}=275.79$, Null deviance of 304.27 on 784 degrees of freedom and Residual deviance of 257.79 on 776 degrees of freedom with the number of Fisher Scoring iterations of 7 . We can also notice that other risk factors including stress, diabetes, kidney failure, and nutrients were removed from the final model. The final predictive factors are presented in Table 3.

The best model analysis allows finding the best Models for the interaction of risk factors amongst themselves, and their association with malformations by applying multinomial regression analysis. The algorithm becomes static after about 1,500 models' iterations around a model that comprises an interaction between high BMI, advanced age, having hypertension, anemia, and infections (see Figure 2).

Once the best model is selected, we recalculate the newly adjusted Odds Ratios of the final predictive model transformed in percentage $(\mathrm{OR} \%)$. Accordingly, we noted the strongest effect of age over 34 to 50 with $376.01 \%$, BMI from 30 to 35 with $130.88 \%$, followed by BMI from 25 to 30 with $103.97 \%$, then infections with $101.56 \%$. A low effect is registered for anemia with $79.23 \%$ and

Table 2. Odds Ratios (OR, 95\% CIs) of different risk factors potentially associated with the malformations.

\begin{tabular}{|c|c|c|c|c|c|c|}
\hline Risk Factors & & variate anal & & & ivariate ana & \\
\hline & OR & $95 \%$ CI & p-value & AOR & $95 \% \mathrm{CI}$ & p-value \\
\hline Age $(24,34]$ & 5.73 & $(1.17-103.62)$ & 0.090 & 4.17 & $(0.81-76.55)$ & 0.172 \\
\hline Age $(34,50]$ & 18.12 & (3.69-327.65) & 0.005 & 10.93 & (2.10-201.71) & $0.023^{*}$ \\
\hline BMI $(25,30]$ & 3.50 & $(1.43-9.83)$ & 0.009 & 2.38 & $(0.91-7.04)$ & 0.091 . \\
\hline BMI $(30,35]$ & 4.33 & (1.68-12.53) & 0.004 & 3.31 & $(1.17-10.36)$ & $0.029 *$ \\
\hline BMI $(35,45]$ & 4.55 & $(0.64-21.07)$ & 0.073 & 3.12 & $(0.37-17.94)$ & 0.234 \\
\hline Stressl & 1.94 & $(0.89-4.86)$ & 0.119 & 1.27 & $(0.52-3.43)$ & 0.613 \\
\hline Diabetes1 & 2.20 & $(0.63-5.88)$ & 0.155 & 1.13 & $(0.29-3.51)$ & 0.840 \\
\hline HT1 & 2.99 & $(1.54-5.79)$ & 0.001 & 2.18 & $(1.04-4.57)$ & $0.038^{*}$ \\
\hline KF1 & 2.61 & $(0.86-6.51)$ & 0.058 & 1.98 & $(0.59-5.60)$ & 0.225 \\
\hline Anemial & 2.25 & $(1.15-4.34)$ & 0.016 & 2.08 & $(0.98-4.35)$ & 0.053 . \\
\hline Infections1 & 3.25 & $(1.68-6.46)$ & 0.001 & 2.64 & $(1.25-5.70)$ & $0.012 *$ \\
\hline Meat2 & 1.91 & (0.88-3.94) & 0.088 & 1.97 & $(0.73-4.98)$ & 0.163 \\
\hline Meat3 & 0.82 & $(0.24-2.20)$ & 0.727 & 0.71 & $(0.14-3.14)$ & 0.669 \\
\hline Fish2 & 1.35 & $(0.39-3.61)$ & 0.589 & 0.93 & $(0.20-3.83)$ & 0.927 \\
\hline Fish3 & 0.68 & $(0.27-1.50)$ & 0.366 & 0.60 & $(0.17-1.81)$ & 0.402 \\
\hline Eggs2 & 1.17 & $(0.48-2.57)$ & 0.709 & 0.78 & $(0.25-2.15)$ & 0.647 \\
\hline Eggs3 & 1.18 & $(0.46-2.68)$ & 0.708 & 2.69 & $(0.76-8.63)$ & 0.106 \\
\hline DP2 & 0.93 & $(0.46-2.02)$ & 0.853 & 1.07 & $(0.47-2.57)$ & 0.875 \\
\hline DP3 & 0.62 & $(0.14-2.05)$ & 0.473 & 0.49 & $(0.09-1.91)$ & 0.342 \\
\hline FV2 & 0.76 & $(0.38-1.51)$ & 0.423 & 0.89 & $(0.40-2.01)$ & 0.783 \\
\hline FV3 & 2.03 & $(0.45-6.59)$ & 0.286 & 3.08 & $(0.56-13.28)$ & 0.154 \\
\hline Cereals2 & 0.89 & $(0.35-2.03)$ & 0.798 & 0.74 & $(0.26-1.90)$ & 0.547 \\
\hline Cereals3 & 1.09 & $(0.47-2.35)$ & 0.830 & 1.10 & $(0.42-2.65)$ & 0.840 \\
\hline Sweets2 & 0.78 & $(0.35-1.64)$ & 0.522 & 0.77 & $(0.31-1.83)$ & 0.565 \\
\hline Sweets3 & 1.13 & $(0.43-2.60)$ & 0.791 & 0.76 & $(0.26-2.02)$ & 0.603 \\
\hline Soft Drinks2 & 0.86 & $(0.38-1.86)$ & 0.695 & 0.93 & $(0.38-2.17)$ & 0.863 \\
\hline Soft Drinks3 & 1.96 & $(0.86-4.29)$ & 0.098 & 1.84 & $(0.74-4.43)$ & 0.177 \\
\hline
\end{tabular}


hypertension with $77.65 \%$. To get a better overview of risk factors on the retained model, Odds Ratio then presented a 95\% CI in a forest model as illustrated in Figure 3. Risk factors appear on the right side of the vertical line of the forest model that represents the risk factor estimate in the general population confirming their positive association with congenital malformations.

To further improve our analysis, we carried out an MCA to analyze the distribution of pregnant women according to the asso- ciated risk factors. The dataset contains 786 women and 46 variables including the risk of congenital malformations and associated factors. The analysis leads to the detection of outliers that strongly influence results. We selected the third and the fourth dimension that opposes women characterized by a strongly positive coordinate (right of the graph) to women characterized by a strongly negative coordinate (left of the graph). These groups share a high frequency for women with hypertension, stress, infections,

Table 3. The generalized linear model of selected risk factors of the congenital malformations model.

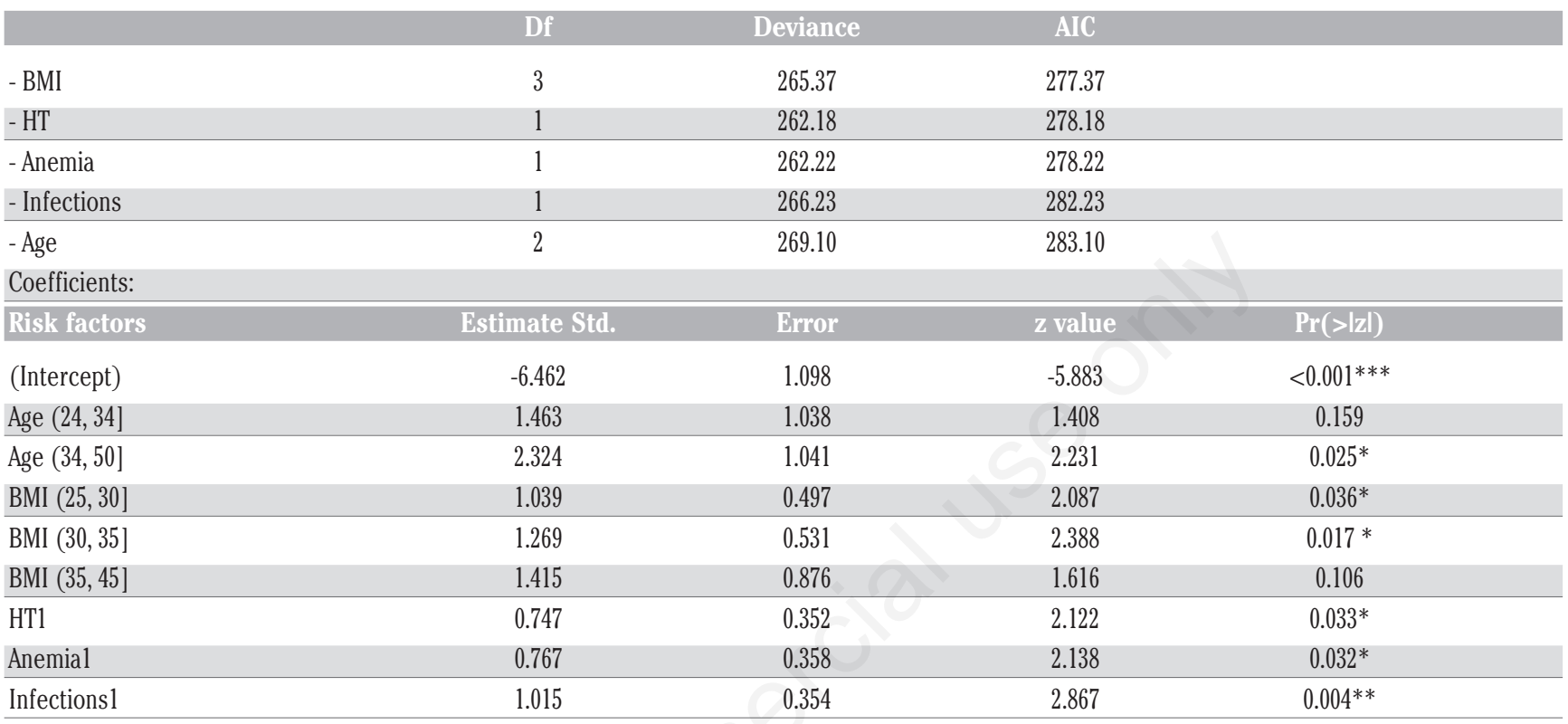

Notes: Signification: For Age and BMI range: "[": indicates that the first value is included in the range, "(": indicates that the first value is not included in the range. *: p<0.1, **: p<0.05, ${ }^{* * *}$ : $p<0.001$. Null deviance: 304.27 on 784 degrees of freedom. Residual deviance: 257.79 on 776 degrees of freedom. AIC: 275.79 . The number of Fisher Scoring iterations: 7.

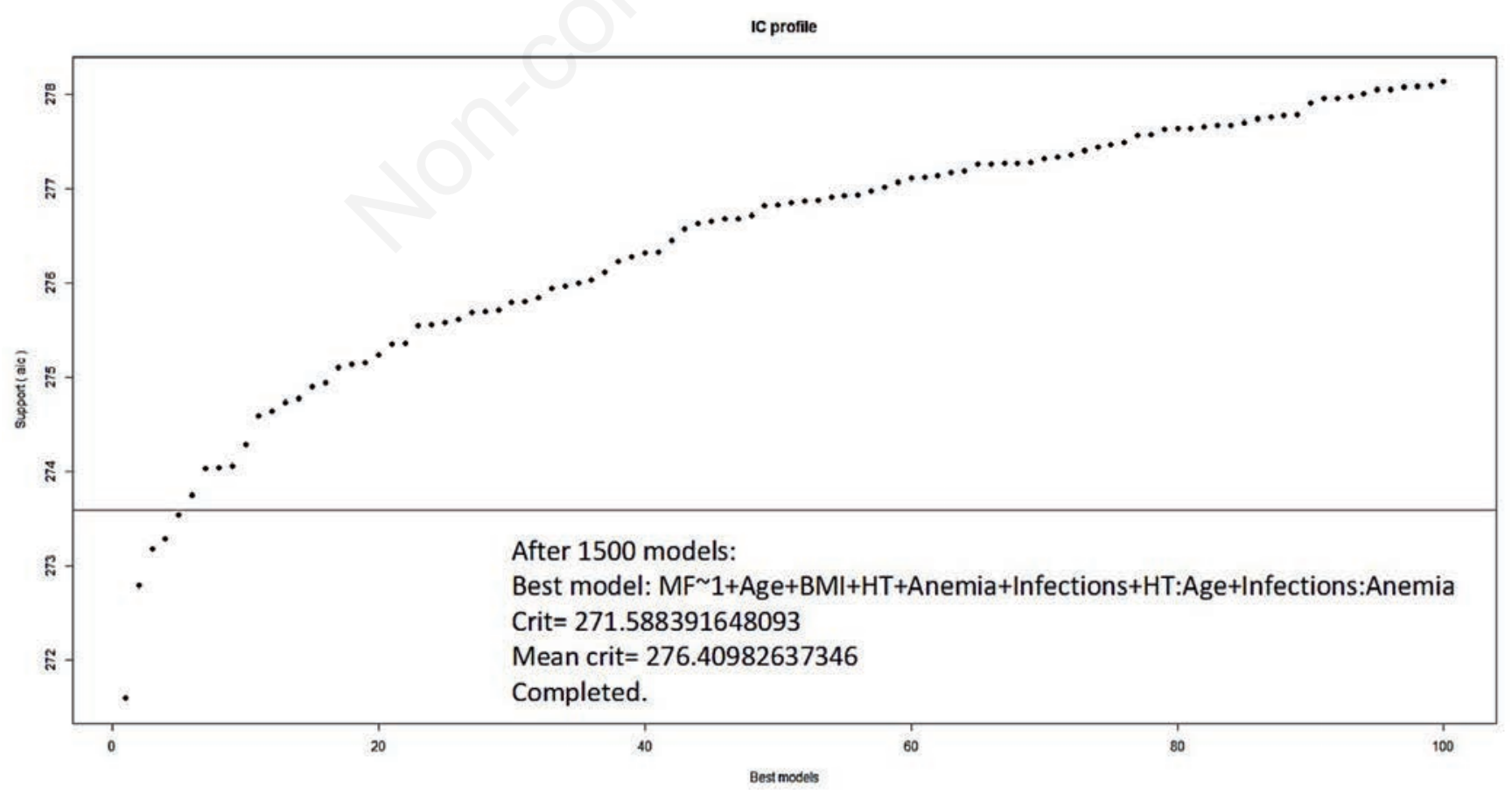

Figure 2. Regression curve for determination of best predictive model of malformations and associated factors. 
kidney failure, age over 34 to 50, BMI from 30 to 35, diabetes, and anemia, and a diet rich in dairy products. Figure 4 illustrates the correlation between all factors most influencing malformations.

Finally, to identify similarities among our population, we carried out an HCA, which allows us to determine the highly correlated factors. In the first step, HCA iteratively gathers factors to generate a clustering tree. Pairs of clusters most similar are successively merged in the dendrogram (see Figure 5). We observe that strongly significant factors are $\mathrm{BMI}>35$, diabetes, and kidney failure. While significant factors are BMI $>30$, Age $>34$, hypertension, stress, anemia, and infections. The second step aims to assemble women according to a similarity criterion defined beforehand. The classification reveals 3 clusters as illustrated in Figure 5. The first cluster includes women sharing a high frequency in case of a diet poor in meat, eggs, fish, cereals, soft drinks, and sweets. The second cluster includes women sharing a high frequency if they have a diet moderate in meat, fish, eggs, dairy products, fruit-vegetables, and sweets. The third cluster includes women sharing a high frequency of stress and a rich diet.

\section{Discussion}

Our study focused on congenital malformations complication and their associated risk factors in pregnant women from Eastern Algeria. We report a high frequency of malformations occurrence, which is associated with an unbalanced or poor diet in general, advanced maternal age, overweight or obesity, and some patholo- gies (hypertension, anemia, infections, stress, and diabetes). These factors may constitute a predictive model for malformations' occurrence.

Therefore, based on the association analysis (Odds Ratio, CI $95 \%$ ), we revealed that malformations are strongly associated with an age from 35 to $50(10.93 ; 2.10-201.71, \mathrm{p}=0.023)$.

A BMI $\geq$ of $25.00 \mathrm{~kg} / \mathrm{m}^{2}$ is associated with an increased frequency of early malformations with a BMI from 25 to 30 (2.38; 0.91-7.04, $\mathrm{p}=0.091)$. Conversely, with a BMI $<25.00 \mathrm{~kg} / \mathrm{m}^{2}$, the chance of having malformations is drastically reduced.

Hypertension ( $2.18 ; 1.04-4.57, \mathrm{p}=0.038)$, anemia (2.08; 0.98$4.35, \mathrm{p}=0.053)$ and infections $(2.32 ; 1.18-4.58 ; \mathrm{p}=0.015)$ are considered as direct risk factors of malformations.

Moderate consumption of meat with OR estimated to 1.97 $(0.73-4.98, \mathrm{p}=0.163)$ and a diet rich in eggs, soft drinks and fruitvegetables are protecting factors against malformations with (2.69; $0.76-8.63, \mathrm{p}=0.106),(1.84 ; 0.74-4.43, \mathrm{p}=0.177)$, and $(3.08 ; 0.56$ $13.28, \mathrm{p}=0.154)$ respectively.

Obtained results are consistent with research in Algeria and around the world. In Algeria, the maternal mortality rate is estimated at around 96.2 maternal deaths per 1000 live births, with around 700 women dying each year from complications during pregnancy or childbirth. For each of these deaths, 30 to 100 women are victims of serious and debilitating complications that can cause permanent disabilities. ${ }^{7}$ Neonatal deaths are closely related to maternal morbidity and mortality. Over the past decade, Algeria has started to implement a maternal mortality reduction process through the national perinatal program, adopted in 2005. The National Plan for Accelerated Reduction of Maternal Mortality
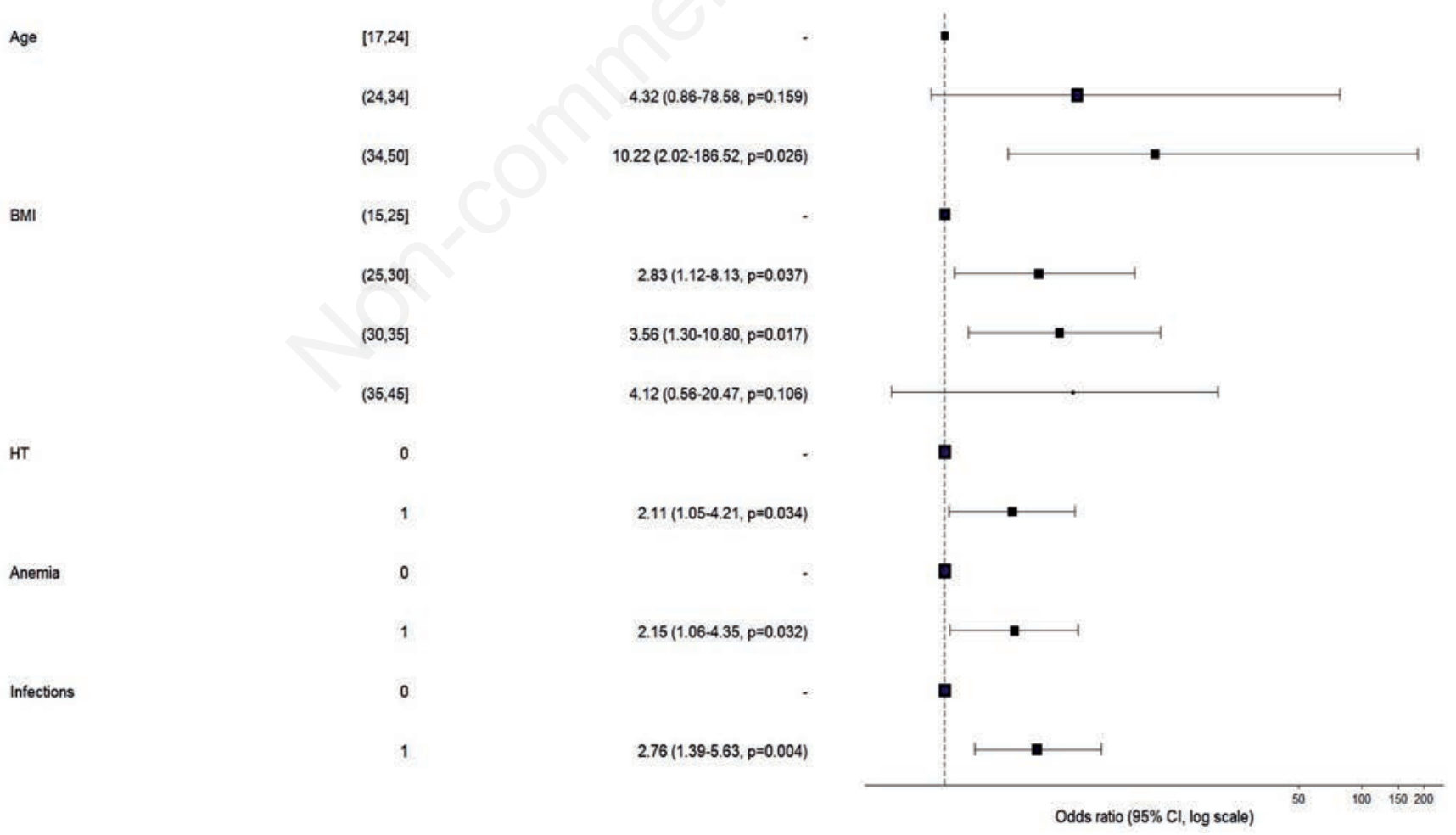

Figure 3. Forest model showing the strength of associated risk factors and their influence on malformations in the predictive model (OR are new adjusted estimates).

Note: For Age and BMI range: "[“: indicates that the first value is included in the range, "(“: indicates that the first value is not included in the range. 
over the 2015-2019 period has been implemented, reflecting Algeria's commitment to regional initiatives in particular the Campaign to Accelerate the Reduction of Maternal Mortality in Africa (CARMMA). The management of maternal health has contributed to a reduction in the Maternal Mortality Rate (MMR). It went from 117.4 deaths per 100,000 live births in 1999 to 57.7 in 2016. Neonatal mortality (deaths under 28 days), meanwhile, is estimated at 17.1 per 1000 live births in 2018 , declined by around $1.2 \%$ per year over the past fifteen years. ${ }^{8}$ Published studies prove that there is a considerable increase in the incidence of malformations cases with increasing age ${ }^{9}$ or because of genetic problems, ${ }^{10}$ even though the majority of works studied the association of only one or a few risk factors.

According to Fuchs et al., ${ }^{11}$ maternal age highly influences pregnancy outcomes. Overweight or obesity in early pregnancy increases the risks of infant mortality, ${ }^{12}$ premature mortality from cardiovascular events in adult offspring, ${ }^{13}$ risk of preterm birth and causes low birth weight. ${ }^{14}$ Weight gain has also a relation with hypertension. ${ }^{15}$ Moreover, we agree with researchers on the fact that hypertension is the most common medical complication during pregnancy. Approximately $70 \%$ of hypertension cases can be attributed to Gestational Hypertension/Preeclampsia (GH-PE). Among $2 \%$ to $5 \%$ of all pregnancies, $\mathrm{GH}$ will progress to preeclampsia. ${ }^{16}$ Hypertensive syndromes affect 6 to $8.0 \%$ of pregnant women and can cause irreparable damage to the fetus. ${ }^{17}$ In our population, like several studies, infections are a direct risk factor of malformations that have harmful effects and can be even considered life-threatening for both mothers and their babies, ${ }^{18}$ namely bacterial vaginosis, ${ }^{19,20} \mathrm{HIV}$, chlamydia, ${ }^{3}$ as well as food poisoning caused by eating contaminated food can generate a wide range of infections and increase the risk of malformation.

A deficiency of nutrients can conduce anemia and influence pregnancy outcomes. In our studied population based on the obtained results, it was remarkable that the daily consumption of fresh fruit-vegetables especially at the 3 months before and after the beginning of pregnancy decreased the risk of malformations.

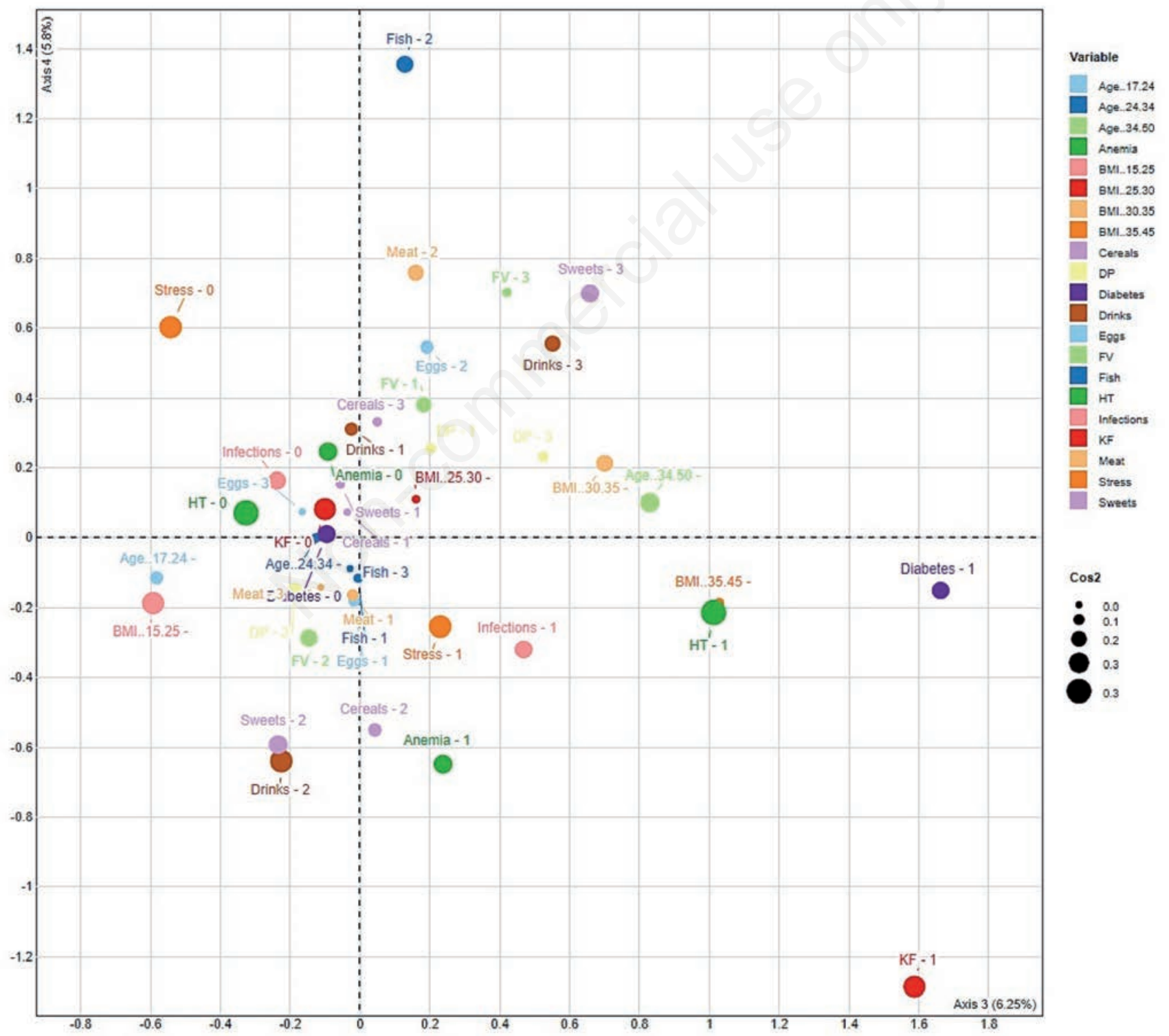

Figure 4. MCA for correlation of malformations' cases and associated factors. 


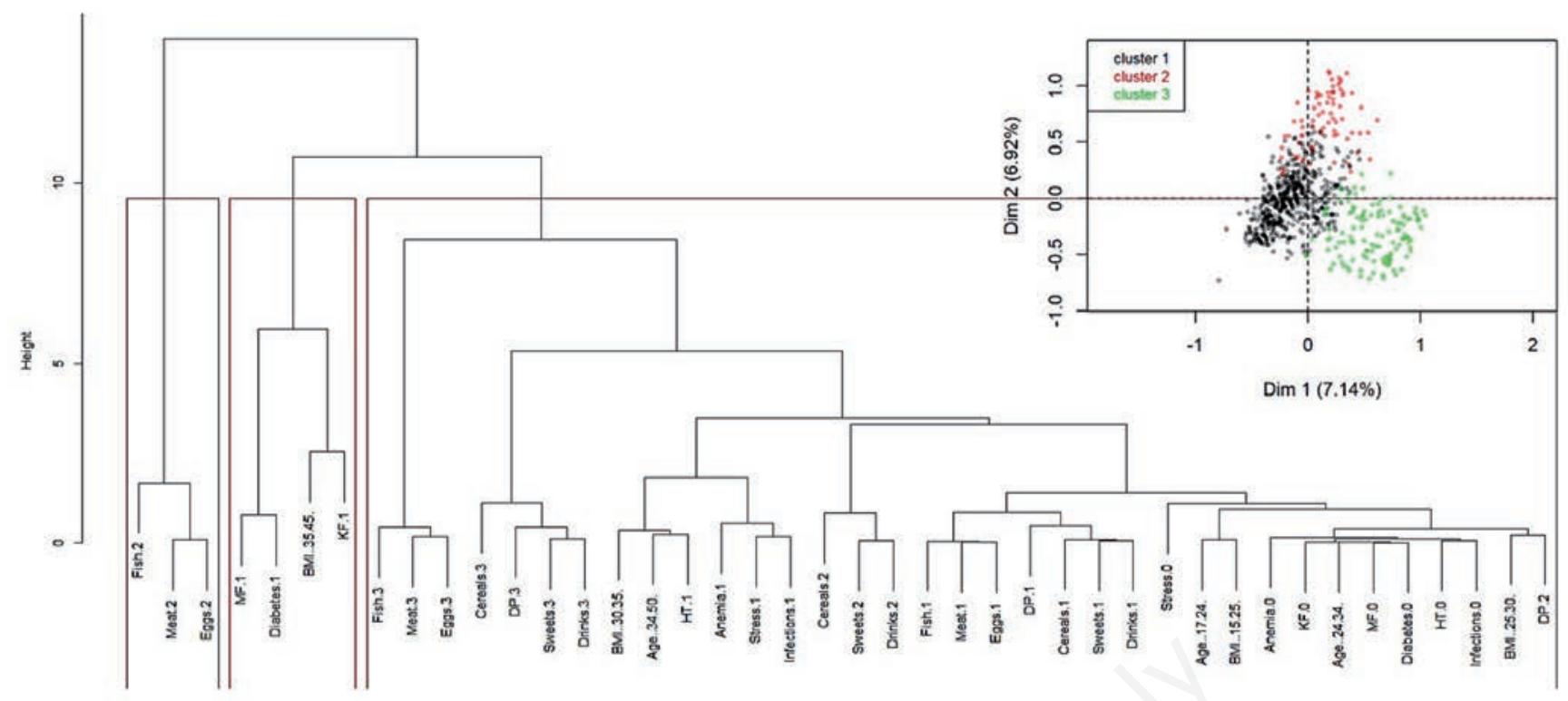

Figure 5. HCA Malformations clusters partition and dendrogram of related risk factors.

The low calcium intake can worsen the severity of last trimester bone loss and the risk of developing preeclampsia. Malnutrition almost exclusively found in animal products, such as eggs, some fruit, and vegetables, generate deficiency of vitamin A and Iodine. ${ }^{21}$ Folates are important in the production of amino acids and certain nucleic acids. They help in the building of new cells, expanding blood volume, and growing tissue. Folate deficiency mainly causes hematological disorders. It may lead to glossitis, depression, anemia, and fetal neural tube, and brain defects. ${ }^{22}$

\section{Conclusions}

Congenital malformation is one of the most frequent risks that may arise during pregnancy because of several factors. Based on the analysis of data collected from 786 pregnant women from Eastern Algeria, we found that there are several factors associated with this risk. The major risk factors reported in this study are maternal age, mother's BMI, pregnancy pathologies, and nutritional deficiency, which result in the tragic outcome of pregnancy. Nutrition is a core element that plays a crucial role, not only in a pregnant woman's health but also that of the future child. Knowing these risk factors helps to establish predictive models and strategies to prevent in Algeria congenital malformations and thus to protect mothers' and babies' health.

Additional studies will allow validating the model and its application to any type of population.

\section{References}

1. Delabaere A, Huchon C, Deffieux X, et al. Épidémiologie des pertes de grossesse. J Gynecol Obstet Biol la Reprod 2014;43:764-75.

2. McClure JH, Cooper GM, Clutton-Brock TH. Saving mothers' lives: Reviewing maternal deaths to make motherhood safer: 20068: A review. Br J Anaesth 2011;107:127-32.

3. Dong DY, Binongo JN, Kancherla V. Maternal chlamydia infection during pregnancy and risk of cyanotic congenital heart defects in the offspring. Matern Child Health J 2016;20:66-76.

4. Boyd PA, Armstrong B, Dolk H, et al. Congenital anomaly surveillance in England-ascertainment deficiencies in the national system. BMJ 2005;330:27.

5. Given JE, Loane M, Garne E, et al. Metformin exposure in first trimester of pregnancy and risk of all or specific congenital anomalies: Exploratory case-control study. BMJ 2018;361:18-20.

6. El Sanharawi M, Naudet F. Comprendre la régression logistique. J Fr Ophtalmol 2013;36:710-5.

7. AFRO. Stratégie de Coopération de l'OMS avec l'Algérie, 2016-2020. OMS/AFRO. Brazzaville, Congo, WHO; 2016. Available from: https://www.afro.who.int/sites/default/files/ 2017-06/ccs-algérie-16-20.pdf

8. Bouklia H. Progression de la mise en œuvre des ODD [Internet]. Algeria; 2019. Avaialble from: http://ambalgott.com/actualite/ ODD.php

9. Haoud K, Mellali S, Gouas L, et al. Prevalence of aneuploidies in products of spontaneous abortion: Interest of FISH and MLPA. Morphologie 2014;98:40-6.

10. Mellali S, Haoud K, Gouas L, et al. Prenatal BoBs ${ }^{\mathrm{TM}}$ in the cytogenetic analysis of products of spontaneous miscarriage. South African Med J 2015;105:870-3.

11. Fuchs F, Monet B, Ducruet T, et al. Effect of maternal age on the risk of preterm birth: A large cohort study. Obstet Gynecol Surv 2018;73:340-2.

12. Johansson S, Villamor E, Altman M, et al. Maternal overweight and obesity in early pregnancy and risk of infant mortality: A Population based cohort study in Sweden. BMJ 2014;349:1-12.

13. Reynolds RM, Allan KM, Raja EA, et al. Maternal obesity during pregnancy and premature mortality from cardiovascular event in adult offspring: Follow-up of 1323275 person years. BMJ 2013;347:1-10. 
14. Ju AC, Heyman MB, Garber AK, Wojcicki JM. Maternal obesity and risk of preterm birth and low birthweight in Hawaii PRAMS, 2000-2011. Matern Child Health J 2018;22:893-902.

15. Heude B, Thiébaugeorges O, Goua V, et al. Pre-pregnancy body mass index and weight gain during pregnancy: Relations with gestational diabetes and hypertension, and birth outcomes. Matern Child Health J 2012;16:355-63.

16. Pan ML, Chen LR, Tsao HM, Chen KH. Prepregnancy endocrine, autoimmune disorders and the risks of gestational hypertension-preeclampsia in primiparas: A nationwide population-based study in Taiwan. Int J Environ Res Public Health 2020;17.

17. Behrens I, Basit S, Lykke JA, et al. Association between hypertensive disorders of pregnancy and later risk of cardiomyopathy. JAMA 2016;315:1026-33.
18. Nelson DB, Hanlon AL, Wu G, et al. First trimester levels of $\mathrm{BV}$-associated bacteria and risk of miscarriage among women early in pregnancy. Matern Child Health J 2015;19:2682-7.

19. Culhane JF, Rauh V, McCollum KF, et al. Maternal stress is associated with bacterial vaginosis in human pregnancy. Matern Child Health J 2001;5:127-34.

20. Nelson DB, Bellamy S, Nachamkin I, et al. Characteristics and pregnancy outcomes of pregnant women asymptomatic for bacterial vaginosis. Matern Child Health J 2008;12:216-22.

21. Gernand AD, Schulze KJ, Stewart CP, et al. Micronutrient deficiencies in pregnancy worldwide: Health effects and prevention. Nat Rev Endocrinol 2016;12:274-89.

22. Scott JM. Evidence of folic acid and folate in the prevention of neural tube defects. Forum Nutr 2001;55:192-5. 